\title{
López Moya, Martín de la Cruz (2010), Hacerse hombres Cabales. Masculinidad entre tojolabales. MÉxico: CIESAS, UNICACH
}

\author{
José Luis Escalona-Victoria
}

A

partir de una aproximación etnográfica a la vida de los habitantes de un pequeño poblado tojolabal de Chiapas, México, Martín López efectuó un estudio acerca de las formas locales de hacerse hombres. El libro nos presenta, así, esas formas específicas de hacerse hombres entre habitantes de un poblado rural del sur de Chiapas, sobre la base de registros etnográficos de interacciones cotidianas y de conversaciones acerca de las expectativas que se tienen sobre los hombres adultos. Cultivar la tierra, viajar, aprender español o tener hijos se vuelven formas locales de mostrar que se es un hombre, en la misma trayectoria de vida y en la convivencia cotidiana. Pero, además de estos registros etnográficos específicos, el análisis de los mismos vincula este caso particular con los estudios sobre masculinidad y género en las ciencias sociales. Por ello, diversos temas presentes en esta literatura de masculinidad y género se tocan en el trabajo de Martín López a partir de un conjunto de ideas básicas: a) las categorías y distinciones de género son producidas socialmente; $b$ ) pueden ser analizadas como representaciones sociales que las personas producen y reproducen cotidianamente - representaciones en términos de entendimientos implícitos o de sentido común, pero también relacionadas con formas de actuar en un modo casi teatral-; c) llevan a la generación de modelos de lo que debe ser socialmente la distinción sexual entre hombres y mujeres y, por ello, contribuyen a la reproducción - competida, disputada - de una de las distinciones básicas de las relaciones de poder. Revisemos el texto a partir de las ideas del autor con respecto a algunos de estos temas, considerando su perspectiva relacional, de proceso y multidimensional del género.

Un primer tema es el del género como una categoría fundacional - entre otras - de la vida social, que tiene implicaciones en la diferenciación de poder, pues produce consecuencias en la demarcación de los espacios, los tiempos y las formas de autoridad, capacidad de representación, participación en ciertos espacios de decisión u oportunidades de aprendizaje y de viaje, por ejemplo. Las prácticas cotidianas generan en sí mismas una diferenciación entre los espacios y tiempos masculinos y femeninos que parecen naturalizar la distinción. El libro nos describe estas formas cotidianas de establecer diferencias cotidianas

José Luis Escalona Victoria. Centro de Investigaciones y Estudios Superiores en Antropología Social, Unidad Sureste, México.

Recibida: 24 de noviembre de 2014. 
entre los habitantes de este pueblo, pero que también están presentes en los pueblos de la región tojolabal. Por ejemplo, la tierra —en propiedad ejidal- está en manos de los hombres, que son a su vez los jefes de familia. Como miembros reconocidos del ejido, ellos son los que asisten a las reuniones o asambleas y son los que ocupan los cargos directivos del ejido. Por ser ellos los proveedores y los representantes de la familia, y a veces de la comunidad ejidal, son también quienes viajan para trabajar o para hacer trámites, por lo que conocen otros lugares y aprenden a hablar más fluidamente el español. Algunos aprenden especialmente a tratar con los funcionarios, comerciantes, empleados de organizaciones y predicadores, o se convierten en ellos al ocupar puestos en la burocracia civil y religiosa o al iniciar negocios más allá de los límites de la comunidad. No es que las mujeres no salgan o no asistan a asambleas ni aprendan a hablar español. El efecto no es diferenciador absoluto, sino relativo, porque más hombres salen, conocen otros contextos y aprenden español, que mujeres. Son, por ejemplo, las mujeres solteras las que más suelen viajar y ganar dinero, o van a trabajar a la milpa en las épocas de más demanda de mano de obra; pero no las casadas. Además, no todas las mujeres solteras salen más allá de las fronteras de la comunidad a viajar, a estudiar, a trabajar o a conocer. En el espacio doméstico, las tareas cotidianas son principalmente responsabilidad de las mujeres, aunque la representación y la autoridad recaen en el hombre adulto; incluso la militancia de los miembros de la familia en organizaciones, iglesias y partidos se define por la preferencia o la militancia del hombre adulto de la casa: la mujer e hijos deben pertenecer a la iglesia y la organización del marido/padre. Al casarse, la mujer debe ir a casa de sus suegros y aprender su forma de vida, que será, ulteriormente, la forma de vida de la casa de su esposo. En general, hay distinciones de espacios, tiempos y prácticas que están atravesados por la distinción de género y producen una condición específica para los hombres frente a las mujeres. Se trata del viejo tema de las diferenciaciones de género en la vida cotidiana. Pero, ¿cómo se producen estas distinciones?
Un segundo tema es el de la contribución que se hace socialmente a la reproducción de esta condición de hombre como un resultado instituido de la masculinidad, pero al mismo tiempo recreado en cada generación. El estudio nos muestra que, más que ser un producto de la condición sexuada del cuerpo, la masculinidad implica una serie de actitudes y de actuaciones que requieren de la valoración y vigilancia de los participantes de las interacciones en su conjunto. En este sentido, es muy ilustrativa la cita de la página 48: "Cuando el chiquero no sirve y el puerco logra salir y dañar los cultivos vecinos, la mujer se queja de la hechura del cerco diciendo: 'Qué ino fue un hombre quien hizo este chiquero?"' También está la referencia al consejo que le da una madre a su hijo: que no se case con una mujer más grande, porque si ella es mayor, no va a poder mandarla. Hacer un chiquero, tener hijos, obligar a una muchacha a tener sexo como una forma de iniciar un matrimonio, mandar en la casa, son no sólo acciones prácticas en sí mismas, con una lógica de fines específicos, sino que también pueden ser actuaciones frente al público, formas de mostrar que se es un hombre ante los demás. Estas acciones son parte de las formas en que la masculinidad se construye socialmente, como un producto del monitoreo de los demás, e incluso en contra de los deseos inmediatos del mismo hombre sujeto a esta socialización. El caso presentado en la introducción es paradigmático en este sentido. Se trata de un hombre casado que trabaja en la clínica y, por ello, aprendió el uso de anticonceptivos y planificación familiar. Él quiere que su esposa use un dispositivo para no tener hijos sin planificación; la esposa se queja y el caso llega hasta la asamblea, en la que el padre y el hermano de la esposa cuestionan a ese hombre como hombre por no querer tener hijos -lo que implica que tal vez no sabe trabajar y mantenerlos, o que no pensó bien que el matrimonio es para eso- La asamblea, a solicitud de la esposa y su familia, es la que demanda a un hombre el ser hombre, el actuar como se espera que lo haga. Las expectativas de las personas y el temor a la mala actuación, la sanción o la vergüenza son parte fundamental de la reproducción de las ideas acerca de qué es ser un hombre. Es decir, no es la condición 
individual de una persona la que lleva a la construcción de un hombre, sino la interacción con los demás. La masculinidad es, entonces, un fenómeno relacional.

Otro tema es el del aprendizaje de esta masculinidad. Hacerse hombres no es una condición, sino un proceso que implica, incluso, un estado cambiante —diría hasta incierta - dependiendo de la actuación de las personas en su trayectoria de vida y, más que eso, de su actuación como hombre en cada momento. No hay una ventaja implícita en los bienes o condiciones de la masculinidad - tierra, esposa o hijos, por ejemplosino que se hace, a partir de ellas, una buena actuación, se representa adecuadamente el papel. La condición de hombre se gana - iganar es la palabra adecuada? - con la forma en que se toma ventaja de las condiciones que la fundamentan — propiedad, trabajo, aprendizaje del español, conocimiento de otros lugares- y se hace una buena actuación frente a los demás al cumplir con las expectativas que del hombre se tienen. Un buen ejemplo de ello está en la descripción que se hace de ciertas formas de matrimonio. En algunos casos, cuando la entrega de la novia ya acordada se retrasa desde la perspectiva del novio y su familia, o cuando hay necesidad de una mujer en casa para el trabajo doméstico, el muchacho casadero es presionado para apurar el matrimonio. Una forma de hacerlo es lo que se llama "jalar a la muchacha": esperar a la chica cuando vuelve del trabajo, aproximarse, tomarla del cabello largo y llevarla aparte para obligarla a tener sexo. El joven y su familia serán sujetos a sanciones por parte de la familia de ella y de las autoridades locales, pero aseguran que la muchacha se casará con el joven y llegará a la casa como nuera. El joven muestra con esta acción que sabe ser hombre, que ha aprendido a serlo, en una acción que, además, es fundamental en la trayectoria del hombre que inicia un matrimonio. Pero esto no es un acto aislado porque su actuación cotidiana está sujeta a la vigilancia de los familiares y vecinos. Aunque, por ejemplo, se acepta que su autoridad puede conducirle a golpear a su esposa e hijos, está siempre sujeto a la evaluación de su actuación: si es responsable o no, si pega con razón y no "de balde". Ser hombre es tener autoridad, pero debe usarla razonablemente de acuerdo con ciertos límites que están siempre en discusión. En general, estas acciones implican un aprendizaje y una evaluación sociales; con ellas, los hombres se hacen y se reafirman $-\mathrm{O}$ no- casi cotidianamente. En ese sentido, el título del libro es afortunado: hacerse hombres cabales. El ser hombre es un proceso social, no una condición.

Un tema más es el de la multiplicidad de representaciones de la masculinidad. El autor utiliza una perspectiva sobre el género en la que, a pesar de hablar de un modelo de masculinidad, de hacerse hombres, se identifican también ciertas formas de manipular y de cuestionar esa idea aparentemente dominante. La idea dominante, de alguna manera ya esbozada, es sintetizada en la noción de hombres cabales: saber pensar, saber actuar, saber trabajar, saber ser responsable, saber representar, saber pegar y castigar. Nuevamente, el caso del aprendiz de ayudante de médico, conocedor de los anticonceptivos y reproductor de un discurso sobre la paternidad responsable, es un buen ejemplo de estos cuestionamientos y de estas reinterpretaciones de hacerse hombres. Dos casos más, presentados también en el libro, resultan interesantes y amplían la visión de los mecanismos fallidos de la imposición de un modelo de masculinidad. Lipe es un hombre casado con hijos y con tierra, es decir, tiene un capital como hombre; sin embargo, no ha representado el papel de hombre adecuadamente, no actúa como hombre ni parece preocuparse por aprender cómo hacerlo ni por la vigilancia de los demás. Parece más bien evadir - no cuestionar - el modelo de masculinidad dominante. Por ello, es un hombre despechado, hecho a un lado y sujeto a burlas por parte de los demás. Incluso enfrentaba una amenaza de ser expulsado del pueblo porque, además de no saber ser hombre, confirmaba su fallo al hacer pequeños hurtos de maíz en las milpas de los vecinos, mostrando así que era haragán y que no podía mantener a su familia por sí mismo. Otro caso es el de Tino, un joven que falló al jalar a la muchacha con la que quería iniciar un proceso de matrimonio, urgido en parte por sus propios padres, que necesitaban una mujer en casa. Tino hizo todo lo prescrito, pero la muchacha logró escapar de él. Por ello, el joven elaboró 
un argumento que permitiera explicar ese fallo que cuestiona la "naturalidad" de la masculinidad: sólo una intervención sobrenatural podía explicar esa actuación fallida: la mujer hizo brujería y le quitó la fuerza que necesitaba para consumar su acción.

Las acciones, entonces, no siempre llevan a la confirmación de la masculinidad de un hombre en particular, sino que pueden, por el contrario, ridiculizar o avergonzar a los participantes. Al mismo tiempo, estas acciones podrían llevar, en algunos casos, a cuestionar en sí mismos los modelos de masculinidad esperados. Podríamos decir, agregando al argumento del autor, que la masculinidad no es sólo un modelo finito, sino también un objeto de reflexión y de entendimiento que se produce y cuestiona en una arena de disputa por lo que significa ser hombre. En síntesis, la masculinidad, de acuerdo con este análisis, no es una condición, sino un proceso; no es individual, es referencial en el contexto de las interacciones cotidianas; y no es unilineal, sino de múltiples dimensiones, disputada, y a veces reelaborada. Es, por todo ello, una construcción social.

En resumen, el estudio de Martín López constituye un análisis de la condición social de la masculinidad -y del género- - Pero, más allá de eso, nos propone una perspectiva relacional, de proceso y multidimensional de la masculinidad. Más que confirmar la presencia - casi evidente- de una distinción masculino/ femenino, los casos permiten un adentramiento en los complejos mecanismos de su reproducción a partir de la colaboración y vigilancia social, la socialización/ aprendizaje y la actuación/representación. Es decir, la masculinidad es el resultado no de mecanismos automáticos de repetición, sino de otros que implican un trabajo de colaboración y de competencia permanentes entre las personas involucradas en la interacción, incluidas las mujeres; es resultado de una vigilancia continua y de un aprendizaje cotidiano que se dan de frente y en referencia a los otros más inmediatos. Es, entonces, un proceso social: se aprende a ser hombre en la interacción. Al mismo tiempo es relacional pues depende, no de los individuos en sus trayectorias personales, sino de los vínculos y las competencias con los otros implicados en los diversos escenarios de la vida cotidiana: la casa, la calle, el trabajo, el matrimonio, la procreación, el viaje, etcétera. El joven aprende a ser hombre y usa las habilidades aprendidas paulatinamente para posicionarse como tal en distintos espacios, como la asamblea, la organización religiosa o política o el trabajo. La masculinidad es, finalmente, multidimensional porque se produce en distintos escenarios y se combina con elementos como el parentesco, la edad o la propiedad, entre otros. Es también de muchas dimensiones pues, a pesar de que se producen modelos o ideas dominantes acerca de lo que debe ser un hombre, también hay formas fallidas de alcanzar el reconocimiento como hombres, como en el caso del joven que falló al raptar a la muchacha como una forma de casarse con ella y que debió buscar explicaciones razonables para explicar el fallo -y evitar así el cuestionamiento y la vergüenza pública-. También hay formas de evasión o de ostracismo frente a los modelos dominantes a pesar de su costo en burla y exclusión, o también están los casos de aquellos que tienen información diferente sobre algún elemento de la actuación como hombres, por ejemplo de la paternidad, y que confrontan de manera directa las vigilancias y los condicionamientos colectivos acerca de lo que es ser un hombre.

Hacerse hombres cabales es un libro que nos hace pensar en la dimensión social del género y que presenta información etnográfica adecuada e interesante. Estudios de este tipo permitirían una más completa aproximación a la dimensión del género como categoría fundamental de la diferenciación social, de la actuación y del cuestionamiento de las relaciones cotidianas de poder. Nos acerca, además, a las incertidumbres que en estas comunidades rurales viven los jóvenes casaderos, las solteras, las nueras, los niños y los que aprenden cosas nuevas sobre la paternidad, la educación o el trabajo. ¿Qué ocurre con las jóvenes que ahora deciden ir a la universidad, o no tener hijos o no casarse?, ¿o con aquellos jóvenes que quieren sólo uno o dos hijos? ¿Qué ocurre con los que no quieren tomar alcohol y buscan más educación y menos trabajo agrícola? Seguramente se puede enriquecer esta perspectiva sobre el género, sobre la construcción social de la masculinidad, 
con estudios que se acerquen a este tema en otras condiciones y localidades, en donde se pueda evaluar, por ejemplo, la presencia de iglesias que promueven el control natal o desprecian el alcoholismo, o de centros de educación superior que estimulan a los jóvenes a mantenerse en la educación profesional y a postergar la paternidad y el matrimonio. Esperamos, entonces, más estudios sobre masculinidad que nos permitan ampliar la mirada sobre los procesos diversos de hacerse hombres en el México contemporáneo. 